Samira Asma

\title{
Smokeless tobacco: betel quid chewing among adult women in Lao People's Democratic Republic
}

$=$

$\therefore$

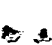

Current address:

Office on Smoking and

Health, National

Center for Chronic

Disease Prevention

and Health Promotion,

Centers for Disease

Control and

Prevention, Mailstop K-50,4770 Buford

Highway, NE, Atlanta, GA 30341-3724, USA; gross national product per capita was US $\$ 320$
sea5@ccdosh1.em.cdc.gov It has a population of 4.7 million, of which

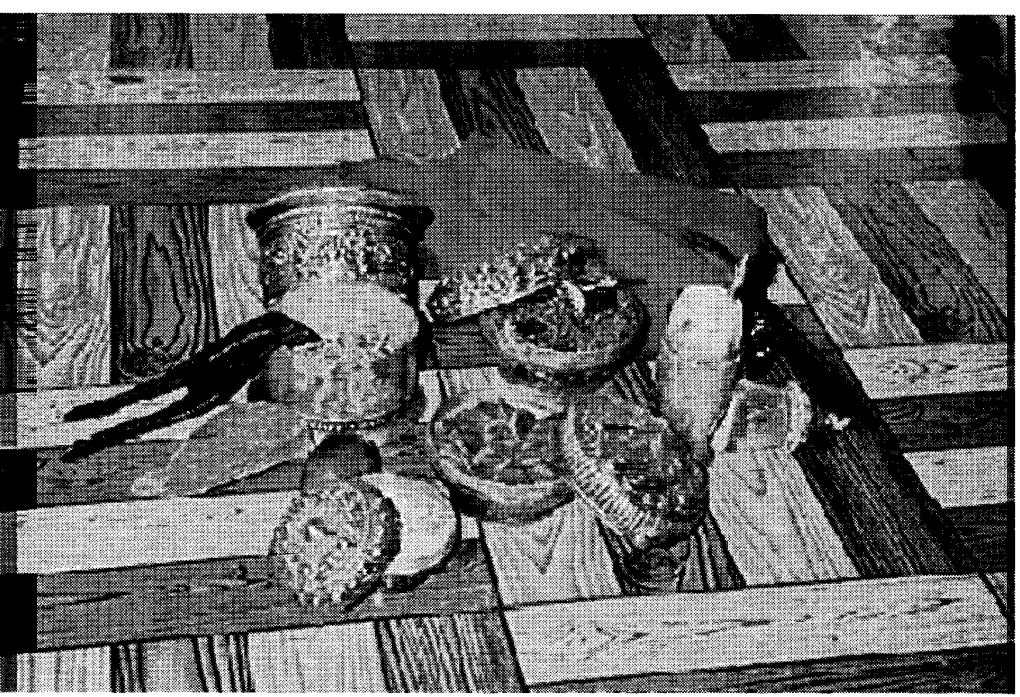

Figure 1 Betel quid ingredients in the Lao People's Democratic Republic are valued so highly that they are carefully kept in handcrafted silver containers.

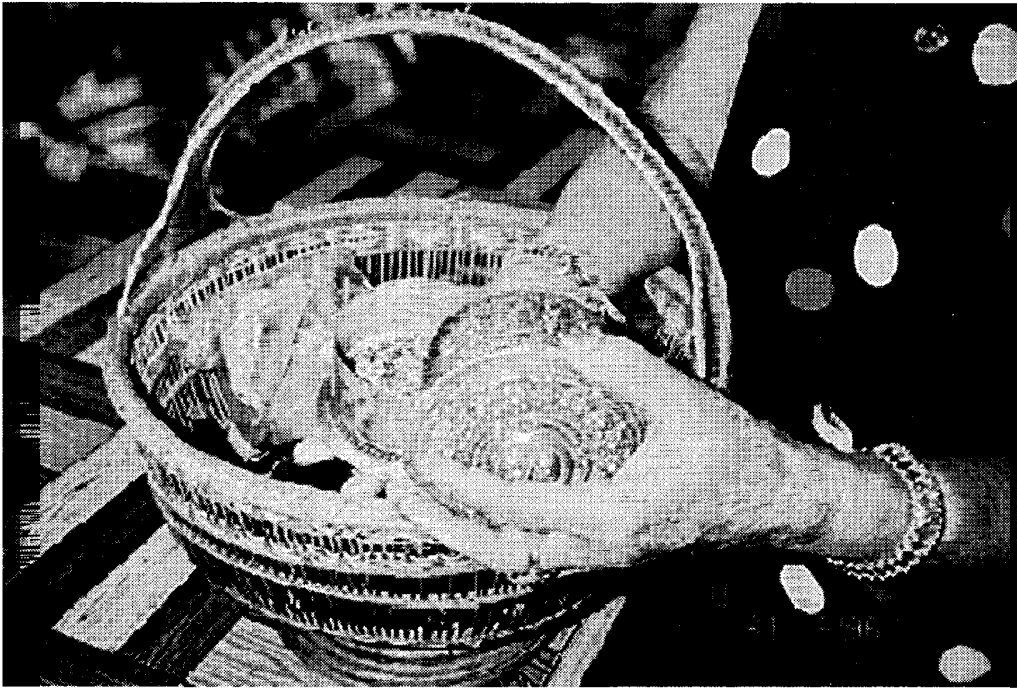

Figure 2 Betel quid ingredients are often kept together in a colourful cane basket.
$85 \%$ live in rural areas. Lao PDR is a tobaccoproducing country. ${ }^{1}$ The total tobacco production was 61600 tonnes/ha in 1995 compared with 5475 tonnes/ha in $1976 .{ }^{2}$ Both smoking and smokeless tobacco use are prevalent in the population. Manufactured and hand-rolled cigarette smoking is a common practice among men, both young and old. Smokeless tobacco in the form of tobacco chewing and betel quid chewing is frequently observed among women.

There are four basic constituents of betel quid: betel leaves (piper betel), areca nut (areca catechu), slaked lime, and tobacco. In Lao PDR, betel leaf is smeared with slaked lime, areca nut is added, and then finely cut tobacco is added to the quid. Betel quid chewing produces excess saliva which is often swallowed. A bright red colour is produced as a result of chewing betel quid, which colours the teeth and mouth red. The most serious outcome of chewing betel quid is squamous cell carcinoma. ${ }^{3}$ Chewing also causes oral leukoplakia and oral submucous fibrosis, both of which are precancerous. ${ }^{4}$

The relationship between smokeless tobacco use and both oral cancer and precancerous lesions is causal. ${ }^{5}$ Long-term use of smokeless tobacco is associated with an increased risk of oral cancer, periodontal disease, and nicotine addiction. ${ }^{6}$ Areca nut chewing is an important aetiological factor for oral submucous fibrosis. ${ }^{7}$ Areca nut contains harmful chemicals including tannins and alkaloids. Arecoline and arecaidine are the main alkaloids that can give rise to carcinogenic nitrosamines in the presence of salivary nitrates. ${ }^{8}$ These alkaloids also have powerful parasympathetic properties, and produce euphoria and counteract fatigue ${ }^{9}$ Moreover, the use of slaked lime helps in quick absorption of nicotine. ${ }^{10}$

Many Laotian women from wealthy families own sets of beautifully handcrafted silver containers in which to keep betel quid ingredients. There are separate containers for dried tobacco flakes, slaked lime paste with a silver stick applicator, sun-dried and fresh-sliced areca nut, an areca nut knife and a cutter, bark of a certain tree, and camphor (used to remove the red stains from the teeth after chewing), all arranged in a colourful cane basket. Betel leaves are kept in a moist cloth to prevent them 


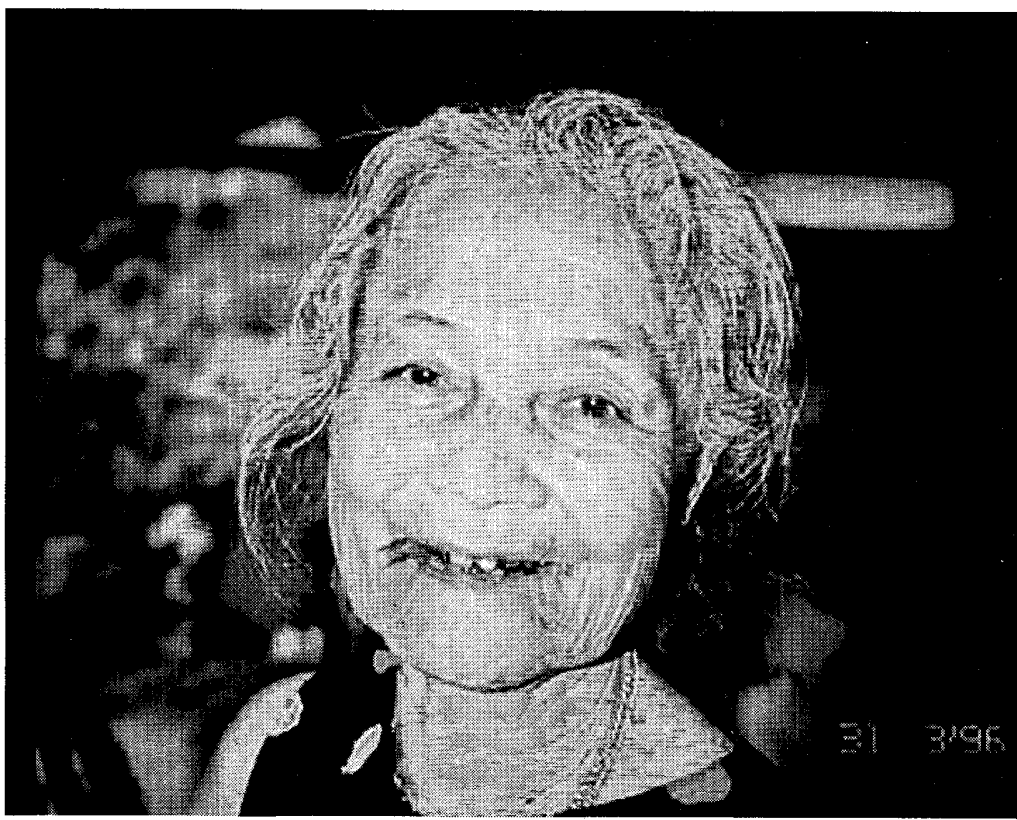

Figure 3 The areca nuts in a betel quid stain the mouths and teeth of betel quid chewers bright red. quid chewing. This may be influenced by differences in educational levels as well as social and cultural phenomena that require further investigation. Better estimates of the prevalence of betel quid chewing in Lao PDR are also needed.

As in all nations, comprehensive tobacco control programmes are needed in Lao PDR, and these programmes will need to be designed to reduce the use of all forms of tobacco use, including betel quid chewing.

1 The World Bank. The World Bank atlas. Washington, DC: The World Bank, 1996.

2 National action plan on tobacco or health-Lao PDR (NAPTH) for 1995-1999. Second draft report 1996. Ministry of Health, Center of Information and Education for istry of Health, Cent

3 Gupta PC, Mehta FS, Daftary DK, et al. Incidence rates of oral cancer and natural history of oral precancerous lesions in a $10 \mathrm{yr}$ follow-up study of Indian villagers. Commun Dent Oral Epidemiol 1980;8:287-333.

4 Gupta PC, Bhonsle RB, Murti PR, et al. An epidemiologic assessment of cancer risk in oral precancerous lesions in India with special reference to nodular leukoplakia. Cancer 1989;63:2247-57.

5 Sinor PN, Gupta PC, Bhonsle RB, et al. A case-control study of oral sub mucous fibrosis with special reference to the etiologic role of areca nut. $f$ Oral Pathol Med 1990;19:94-8.

6 US Department of Health and Human Services. The health consequences of using smokeless tobacco. $A$ report of the consequences of using smokeless tobacco. A report of the
advisory committee to the Surgeon General. Bethesda, Maryadvisory committee to the Surgeon General. Bethesda, Maryland: Public Health Service, National

from drying. A red cloth is an essential part the basket, which is used for cleaning the red-coloured saliva as a result of betel quid chewing (figures 1-3).

Preliminary observations of betel quid chewing in Lao PDR in early 1996 suggest that the problem may be widespread. Laotian women were observed to frequently chew 7-10 betel quids per day. Even though this form of tobacco use, like all others, is addictive and dangerous, it appears that few Laotian women are aware of the serious health hazards of betel
Bhonsle RB, Murti PR, Gupta PC, et al. Regional variations in oral submucous fibrosis in India. Commun Dent Oral Epidemiol 1987;15:225-9.

8 International Agency for Research on Cancer. IARC monographs on the evaluation of the carcinogenic risk of chemicals to humans. Vol 37. Tobacco habits other than smoking; betel-quid and areca-nut chewing; and some related nitrosamines. Lyon: IARC, 1985.

9 Caniff JP, Harvey W, Harris M. Oral submucous fibrosis: I. Its pathogenesis and management. Brit Dent $\mathcal{F} 1986$; 160:429-34.

10 Gupta PC, Pindborg JJ, Mehta FS. Comparison of carcinogenicity of betel quid with and without tobacco: an epidemiological review. Ecol Dis 1982;1:213-9.

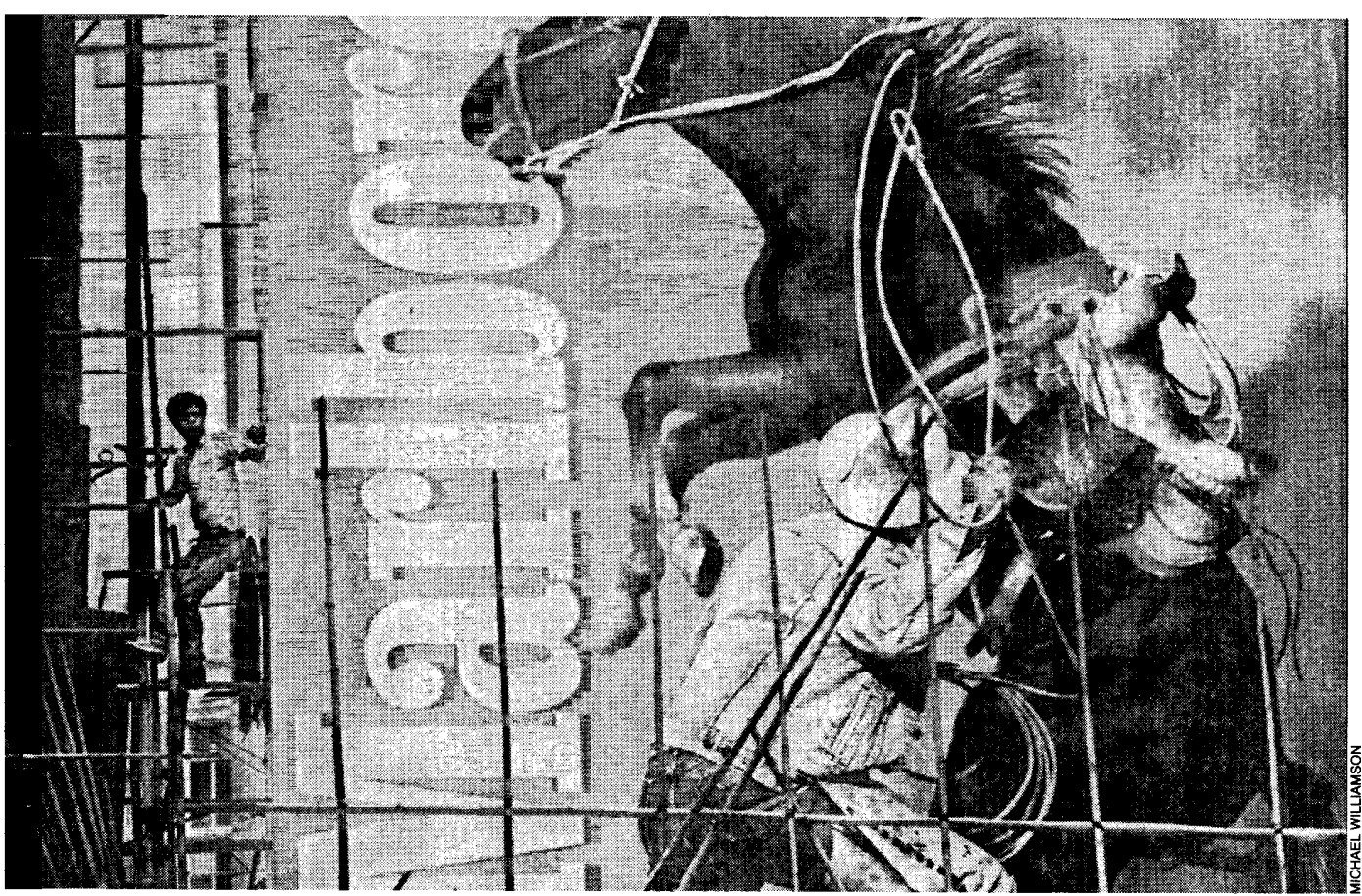

$A$ worker puts finishing touches on a giant Marlboro billboard in Hong Kong. Source: Washington Post, 17 November 1996.

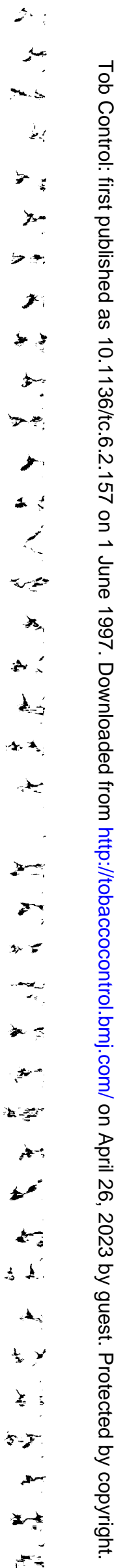

